\title{
Magnezyum Alaşımının DLC Kesici Takımlarla Frezelenmesi
}

${ }^{* 1}$ Mustafa Ay, ${ }^{2}$ Gültekin Basmac1, ${ }^{3}$ Ayhan Etyemez, ${ }^{4}$ Mert Türk

${ }^{1}$ Teknoloji Fakültesi, Makine Mühendisliği Bölümü Marmara Üniversitesi,, İstanbul, Türkiye

${ }^{2}$ Mühendislik-Mimarlık Fakültesi, Makine Mühendisliği Bölümü Burdur Mehmet Akif Ersoy Üniversitesi,

Burdur, Türkiye

${ }^{3}$ Nikken, Istanbul, Türkiye

${ }^{4}$ Marmara Üniversitesi Fen Bilimleri Enstitüsü Göztepe İstanbul

\section{Özet}

$\mathrm{Bu}$ çalışmada magnezyum alaşımı malzemenin DLC (elmas benzeri kaplama) frezeleme kesici takımlarla frezelenmesinde ilerleme, kesme hızı ve talaş derinliğinin yüzey bütünlüğüne ve kesme kuvvetlerine etkisi araştırılmıştır. Deney tasarımında Taguchi metodu kullanılmıştır. Bu metot ile deneylere harcanacak zaman ve maliyetten tasarruf edilmiş, deney sonuçlarında elde edilen veriler optimize edilerek iyileştirme gerçekleştirilmiştir. Gri ilişki analizi ile A1B1C1 deney serisinde uygun değer kesme şartları belirlenmiştir.

Anahtar Kelimeler: Magnezyum, DLC Kesici Takım, Frezeleme, Taguchi, Gri İlişkisel Analizi

\section{Milling of Magnesium Alloy with DLC Cutting Tools}

\begin{abstract}
In this study, the effect of cutting force and surface roughness, cutting speed and cutting depth on milling of magnesium alloy material by DLC (Diamond Like Coating) milling cutting tools is investigated. Taguchi method was used for experiment design. With this method, the time and cost to be spent on the experiments were saved, and the data obtained in the experimental results are optimized, and improvement was carried out.
\end{abstract}

Key Words: Magnesium, DLC cutting tool, Milling, Taguchi, Gray Relational Analysis

\section{Giriş}

Havacılık, savunma, elektronik, medikal ve otomotiv sektörleri gibi birçok endüstriyel uygulamada, hafif mühendislik malzemelerine olan talep sürekli artmaktadır. Hafiflik ve dayanım açısında titanyum ve alüminyum alaşımları tercih edilen mühendislik malzemeleridir. Diğer yandan magnezyum alaşımları da bu sektörlerde kullanılan diğer bir mühendislik malzemesidir.

Magnezyum dünya üzerinde en bol bulunan elementlerden biridir ve yer kabuğunun ağırlıkça yaklaşık \%2,7'sini teşkil eder ki en çok bulunan sekizinci elementtir ve altıncı metaldir [1]. Magnezyumun yoğunluğu $1,74 \mathrm{gr} / \mathrm{cm}^{3}$ olup, yapısal uygulamalarda kullanılan en hafif metaldir. Ağırlığı alüminyumun üçte ikisi, demirin dörtte biri, bakır ve nikelin ise beşte biri düzeyindedir. Alaşım yapıldığında mekanik özellikleri iyileşir. Magnezyum alaşımları yüksek dayanım-düşük yoğunluk, işlenebilirlik, dökülebilirlik, titreşim sönümleme gibi iyi özelliklerine sahiptirler. Düşük ergime sıcaklığı $\left(650^{\circ} \mathrm{C}\right)$ ve iyi kaynak kabiliyetine sahip olan magnezyum, doğada yaygın olarak bulunabilmektedir. Bu nedenle elektronik, otomotiv endüstrisinde, uçak ve havacılık sanayinde geniş kullanım alanına sahiptir [1-4].

Günümüzde magnezyum alaşımlarına olan en büyük ilgi otomotiv endüstrisi tarafindan gelmektedir. Bu ilginin karşılığı olarak magnezyum alaşımlı otomotiv parçalarının artmasının 
başlıca sebebi, hafif magnezyum alaşımları kullanılarak araç ağırlığında oluşturulan azalmanın yakıt ekonomisine katkı sağlaması ve bunun sonucu olarak araçlardaki gaz emisyonlarının da azaltılabilmesinin mümkün olmasıdır [2-9]. Magnezyum uçak motorlarında, iskeletinde ve iniş takımlarında yoğun biçimde kullanılmaktadır. Uygun sıcaklıkta, yorulma ve çarpmaya karşı iyi özellikleri ve de kolay işlenebilmesi yanında, magnezyumun kullanılmasını gerektiren ana faktörler; dökümlerdeki kopma mukavemeti/ağırlık ve dövülmüş parçalardaki burkulma dayanımı/ağırlık oranıdır [9].

AZ91 alaşımının işlenmesi amacıyla yapılan çalışmalarda, Akyüz yapmış olduğu çalışmada, $\mathrm{AZ}$ serisi Mg alaşımının içerindeki alüminyumun etkisini araştırarak, kesme hızının artması ile kesme kuvvetlerinin arttı̆̆ görülmüştür [8]. Kim ve Lee yaptıkları çalışmada, AZ31B Mg alaşımının kuru kesme şartlarında freze çakısı üzerindeki uç sayısının ve diş başına ilerlemenin artmasıyla yüzey pürüzlülük değerinin artığını, ancak kesme hızı belirli bir aralığında yüzey pürüzlülük değeri değişmemiş ve soğutulmuş hava akışıyla azalmıştır [9]. Narita ve arkadaşları yaptıkları çalışmada, AZ91 magnezyum alaşımında kesme dayanımını, yüzey pürüzlülügünü, talaş uzunluğunu ve kalınlığını ölçerek test etmişler, kesme dayanımı hem ilerleme miktarının hem de talaş derinliğinin artması ile artmış ve yan talaş açısının artmasıyla azalmıştır. Kesme hızının azalmasıyla ve ilerleme miktarının artmasıyla talaşın boyu azalmıştır. AZ91 magnezyum alaşımının yüksek hızlarda işlenmesinde yüzey pürüzlülüğü çok iyidir [10].

Bu çalışmada magnezyum alaşımı malzemenin DLC (elmas benzeri kaplama) frezeleme kesici takımlarla frezelenmesinde ilerleme, kesme hızı ve talaş derinliğinin yüzey bütünlüğüne ve kesme kuvvetlerine etkisi araştırılmıştır. Deney tasarımında Taguchi metodu kullanılmıştır. Bu metot ile deneylere harcanacak zaman ve maliyetten tasarruf edilmiş, deney sonuçlarında elde edilen veriler optimize edilerek iyileştirme gerçekleştirilmiştir. Gri ilişki analizi ile A1B1C1 deney serisinde optimum kesme şartları belirlenmiştir.

\section{Materyal ve Yöntem}

\subsection{Materyal}

AZ91 yüksek dayanım ve iyi dökülebilme özelliğine sahiptir. Araştırmada kullanılan malzeme magnezyum alaşımı olan AZ91 serisidir. Tablo 1 de malzemeye ait bileşenler ve Tablo 2'de de mekanik özellikleri gösterilmiştir.

Tablo 1. Magnezyum Alaşımları Ve Kimyasal Bileşimleri

\begin{tabular}{ccccccccccc}
\hline $\begin{array}{c}\text { Alaşım } \\
\text { Elementi }\end{array}$ & $\mathrm{Al}$ & $\mathrm{Zn}$ & $\mathrm{Mn}$ & $\begin{array}{c}\mathrm{Si} \\
(\max )\end{array}$ & $\begin{array}{c}\mathrm{Fe} \\
(\max )\end{array}$ & $\mathrm{Cu}$ & $\begin{array}{c}\mathrm{Ni} \\
(\max )\end{array}$ & $\mathrm{Be}$ & Diğer & $\mathrm{Mg}$ \\
\hline $\mathrm{AZ91}$ & $8,5-9,5$ & $0,45-$ & $0,17-$ & 0,05 & 0,004 & 0,025 & 0,001 & - & 0,01 & Kalan \\
\hline
\end{tabular}

Kullanılan magnezyum alaşımının ölçüleri $(150 * 150 * 10) \mathrm{mm}$ 'dir.

Tablo 2. AZ 91 Mekanik Özellikleri

\begin{tabular}{ccccc}
\hline & $\begin{array}{c}\text { Akma Muk. } \\
(\mathrm{MPa})\end{array}$ & $\begin{array}{c}\text { Çekme Muk. } \\
(\mathrm{MPa})\end{array}$ & $\begin{array}{c}\text { Uzama } \\
(\%)\end{array}$ & $\begin{array}{c}\text { Elastiklik Mod. } \\
(\mathrm{Gpa})\end{array}$ \\
\hline AZ 91 & 168 & 311 & 21 & 49 \\
\hline
\end{tabular}




\subsection{Deney Düzenĕgi}

Frezeleme için yüksek devirlerde ve DLC kesici takımlar ile çalışılması gerekmektedir. Deneylerde JOHNFORD VMC-850/550+APC CNC Fanuc 0T x-y-z eksenli freze tezgahında, yüksek hız devir sağlayıcı olarak Nikken marka hız kafası CNC işleme merkezine adapte edilmiştir. Hız kafasının iç koniği SK10-10A normunda pens kullanılmıştır. Deneyde kullanılan 10mm çapında DLC parmak freze kullanılmıştır. MAHR-Perthometre cihazı ile yüzey pürüzlülüğü ölçülmüştür. Kuvvet ölçümü için KISTLER 9265B kuvvet sensörü, KISTLER 5080 yük amplifikatörü ve analiz programı olarak DynaWare programı kullanılmıştır (Şekil 1).

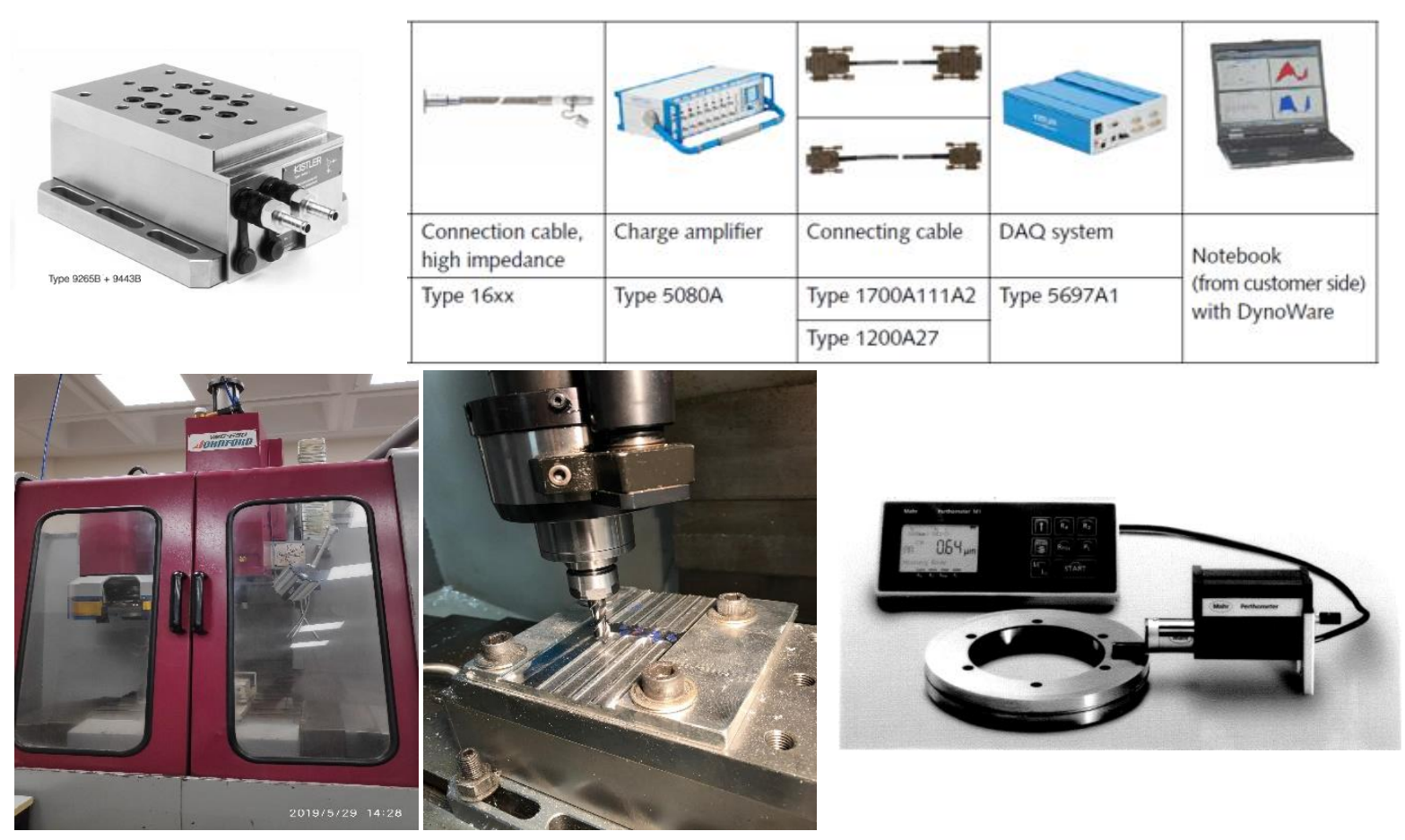

Şekil 1. Deney Düzeneği

\subsection{Deney Tasarımı}

Malzeme özellikleri, devir sayısı, ilerleme miktarı ve talaş derinliği gibi parametreler kesme şartlarını oluşturmaktadır. Taguchi metodu deney sayısını azaltarak, test ve üretim maliyetlerinin azalmasını sağlamaktadır [11-15].

Deneyler Taguchi yöntemi ile tasarlanmıştır. İlk olarak, kontrol faktörü ve seviyeler belirlenmiştir. Sonrasında matris seçimi yapılarak, seviyeler matrise aktarılmıştır. Kullanılan L9 dizine göre değişkenlerin üç farklı seviyesi bulunmaktadır. Toplam 9 farklı deney yapılmıştır.

$\mathrm{Bu}$ araştırmada ki değişkenler ve seviyeler Tablo 3'de verilmiştir. 
Tablo 3. Değişkenler ve Seviyeler

\begin{tabular}{lclcrcc}
\hline Değişkenler & Sembol & Birim & Kod & \multicolumn{3}{c}{ Seviyeler } \\
\hline & & & & 1 & 2 & \multicolumn{1}{c}{3} \\
\cline { 4 - 7 } Devir & $\mathrm{n}$ & $\mathrm{m} /$ dak & $\mathrm{A}$ & 9000 & 10000 & 11000 \\
İlerleme miktarı & $\mathrm{f}$ & $\mathrm{mm} / \mathrm{dak}$ & $\mathrm{B}$ & 800 & 1000 & 1200 \\
Talaş derinliği & $\mathrm{d}$ & $\mathrm{mm}$ & $\mathrm{C}$ & 0.5 & 1.0 & 1.5 \\
\hline
\end{tabular}

Aşağıda Tablo 4'de Taguchi yöntemine göre tasarlanan deneylerin listesi belirtilmiştir. Toplamda yapılan deney sayısı 9 olmuştur.

Tablo 4. Deney Tasarımı

\begin{tabular}{ccccc}
\hline $\begin{array}{c}\text { Deney } \\
\text { No }\end{array}$ & Değişkenler & $\begin{array}{c}\text { Kesme hız1 } \\
(\mathrm{m} / \mathrm{dak})\end{array}$ & $\begin{array}{c}\text { İlerleme } \\
(\mathrm{mm} / \mathrm{dev})\end{array}$ & $\begin{array}{c}\text { Kesme derinliği } \\
(\mathrm{mm})\end{array}$ \\
\hline 1 & A1B1C1 & 1 & 1 & 1 \\
2 & A1B2C2 & 1 & 2 & 2 \\
3 & A1B3C3 & 1 & 3 & 3 \\
4 & A2B1C2 & 2 & 1 & 2 \\
5 & A2B2C3 & 2 & 2 & 3 \\
6 & A2B3C1 & 2 & 3 & 1 \\
7 & A3B1C3 & 3 & 1 & 3 \\
8 & A3B2C1 & 3 & 2 & 1 \\
9 & A3B3C2 & 3 & 3 & 2 \\
\hline
\end{tabular}

\subsection{Gri İlişkisel Analiz (GIA)}

Gri İlişkisel Analizi’nde; siyah, bilgiye sahip olmadığını, beyaz, bilgiye tamamen sahip olduğunu gösterir. Gri sistem ise, siyah ile beyaz arasındaki bilginin seviyesini gösterir. Diğer bir deyişle gri sistemde bazı bilgiler bilinirken bazı bilgiler bilinmez. Beyaz sistemde, sistem içerisindeki ilişkiler arası faktörler kesindir. Gri sistemde ise sistem içerisindeki ilişkiler arası faktörler kesin değildir [11].

Gri ilişkisel analiz (GİA) gri modellemenin alt başlıklarından biridir. GİA gri bir sistemdeki her bir faktör ile kıyas yapılan faktör (referans serisi) serisi arasındaki ilişki derecesini belirlemeye yarayan bir metottur. Her bir faktör bir dizi (satır veya sütun) olarak tanımlanır. Faktörler arası etki derecesi ise gri ilişkisel derece olarak isimlendirilir [11-14].

Gri ilişkisel analiz metodunun hesaplama adımları aşağıdaki gibidir [11-14]:

1.Adım: $\mathrm{n}$ uzunluğundaki referans seri aşağıdaki gibi olsun (Eşitlik 1).

$$
x_{0}=\left(x_{0}(1), x_{0}(2), x_{0}(3), \ldots, x_{0}(n)\right)
$$

\section{Adım: Verilerin normalize edilmesi}

Faktörlerin farklı kaynaklardan geldiği, farklı birimlerde ölçüldüğü düşünüldügünde GİA' nın ilk adımı verilerin aynı birime dönüştürülmesidir. Ayrıca serinin çok geniş aralıklarda değerler aldığı durumlarda standartlaştırmayla verilerin küçük bir aralığa çekilmesinde de fayda vardır. Gri sistem teorisinde bu normalleştirme projesine "gri ilişkisel oluşum (grey relational generating)" adı verilmektedir. Verilerin normalizasyonunda en sık kullanılan yöntemlerden 
birisi lineer veri önişleme metodudur. Faktör serilerinin normalizasyonunda dikkat edilmesi gereken " daha yüksek daha iyi", "daha düşük daha iyi” ve "en ideal en iyi” kriterlerinden hangisinin serinin özelliğini yansıttı̆gıdır. Örneğin serideki noktaların küçük değerler olması istenen bir özellik ise lineer normalizasyonda küçük değer alan noktalar normalizasyonda "1" e yakın değerler alırken, büyük değer alan noktalar " 0 " 'a yakın değerler alacaktır.

“Daha yüksek daha iyi” durumunda normalizasyon Eşitlik 2'deki gibidir.

$$
x_{i}(k)=\frac{x_{i}^{0}(k)-\min x_{i}^{0}(k)}{\max x_{i}^{0}(k)-\min x_{i}^{0}(k)}
$$

x0 (k ), i serisi k. sıradaki orjinal değer, xi $(\mathrm{k})$ normalizasyon sonrası i. seri k. Sırasındaki değer, min x0 (k ) i serisindeki minimum değer, max x0 (k) i serisindeki maksimum değerdir.

"Daha düşük daha iyi” için Eşitlik 3'deki gibidir;

$$
x_{i}(k)=\frac{\max x_{i}^{0}(k)-x_{i}^{0}(k)}{\max x_{i}^{0}(k)-\min x_{i}^{0}(k)}
$$

“İdeal değer daha iyi” için Eşitlik 4'deki gibidir;

$$
x_{i}(k)=1-\frac{\left|x_{i}^{0}(k)-x^{0}\right|}{\max x_{i}^{0}(k)-x^{0}}
$$

Burada $x^{0}$ istenilen ideal değeri göstermektedir.

1. Adım: $x_{0}$ serisi ile karşılaştırılacak m tane seri Eşitlik 5'de tanımlanmış olsun.

$$
\text { x (x ),1( x ),2( x 3( ), .., x (n)) i = i i i i i }=2,1, \ldots, m
$$

2. Adım: k, n uzunluğundaki serideki k. Sırayı göstersin n, $\varepsilon(\mathrm{x} 0(\mathrm{k}), \mathrm{xi}(\mathrm{k}))$ noktadaki gri ilişkisel katsayı olup eşitlik 6, 7, 8 ve 9'a göre hesaplanır.

$$
\begin{aligned}
& \varepsilon\left(x_{0}(k), x_{i}(k)\right)=\frac{\Delta_{\text {min }}+\xi \Delta_{\text {min }}}{\Delta_{0 \mathrm{i}}(k)+\xi \Delta_{\max }} \\
& \Delta_{0 i}(k)=\left|x_{0}(k)-x_{j}(k)\right| \\
& \Delta_{\text {min }}=\min _{j} \min _{k}\left|x_{0}(k)-x_{j}(k)\right| \\
& \Delta_{\text {max }}=\max _{j} \max _{k}\left|x_{0}(k)-x_{j}(k)\right|
\end{aligned}
$$

3. Adım: Son olarak gri ilişkisel derece ise eşitlik 10 ile hesaplanır:

$$
\gamma\left(x_{0}, x_{i}\right)=\frac{1}{n} \sum_{k=1}^{n} \varepsilon\left(x_{0}(k), x_{i}(k)\right)
$$


$\gamma(\mathrm{x} 0, \mathrm{xi})$, xi x0, benzerliği n bir ölçüsüdür. Gri ilişkisel derecesinin büyüklüğü xi ile x0 arasında kuvvetli bir ilişki olduğunu $n$ göstergesidir. Eğer karşılaştırılan iki seri birbirinin aynı ise gri ilişkisel derece değeri 1 olarak bulunur. Gri ilişkisel derece karşılaştırılan serinin referans seriye ne kadar benzer olduğunu gösterir.

Eğer her bir kriterin ağırlıkları verildiyse, kriterin gri ilişki katsayısı ile kriterin önem derecesine ilişsin ağırlık değeri çarpılarak gri ilişki derecesi bulunabilir. Bu Eşitlik 11'e göre hesaplanır.

$\gamma\left(x_{0}, x_{i}\right)=\frac{1}{n} \sum_{k=1}^{n} \varepsilon\left(x_{0}(k), x_{i}(k) .\left(\mathrm{W}_{i}(\mathrm{k})\right)\right)$

Karar verme probleminde referans seri, kriterlerin alması istenen en büyük, en küçük ve en ideal değerler olarak seçilirse, karşılaştırması yapılacak faktör serinin referans seriye göre hesaplanacak gri ilişkisel derecesi kriterleri yakalama seviyesinin bir göstergesi olacaktır. Diğer bir deyişle gri ilişkisel derecesi en yüksek olan faktör serisi (alternatif) karar verme probleminde en iyi karar verme alternatifini gösterecektir.

\section{Bulgular Ve Tartışma}

\subsection{Sinyal/Gürültü̈ Oranları ve En Uygun Seviyeler}

Taguchi tasarımı ile elde edilen sonuçlar sinyal/gürültü $(\mathrm{S} / \mathrm{N})$ oranlarına dönüştürülmekte ve desibel (dB) olarak ifade edilmektedir. Sinyal değeri sistemin verdiği ve ölçülmek istenen gerçek değeri, gürültü faktörü ise ölçülen değer içerisindeki istenmeyen faktörlerin payını temsil etmektedir [15]. Çalışmamızda hedef en iyi yüzey kalitesine ve en düşük kesme kuvvetine ulaşmak olduğu için Sinyal/Gürültü oranı için kullandığımız denklem en küçük en iyi denklemidir [15]. Şekil 2 ve 3'de S/N oranı verilmiştir.

$$
S / N=10 x \log \left(\frac{1}{n} \sum_{i=1}^{n} y_{i^{2}}\right)
$$

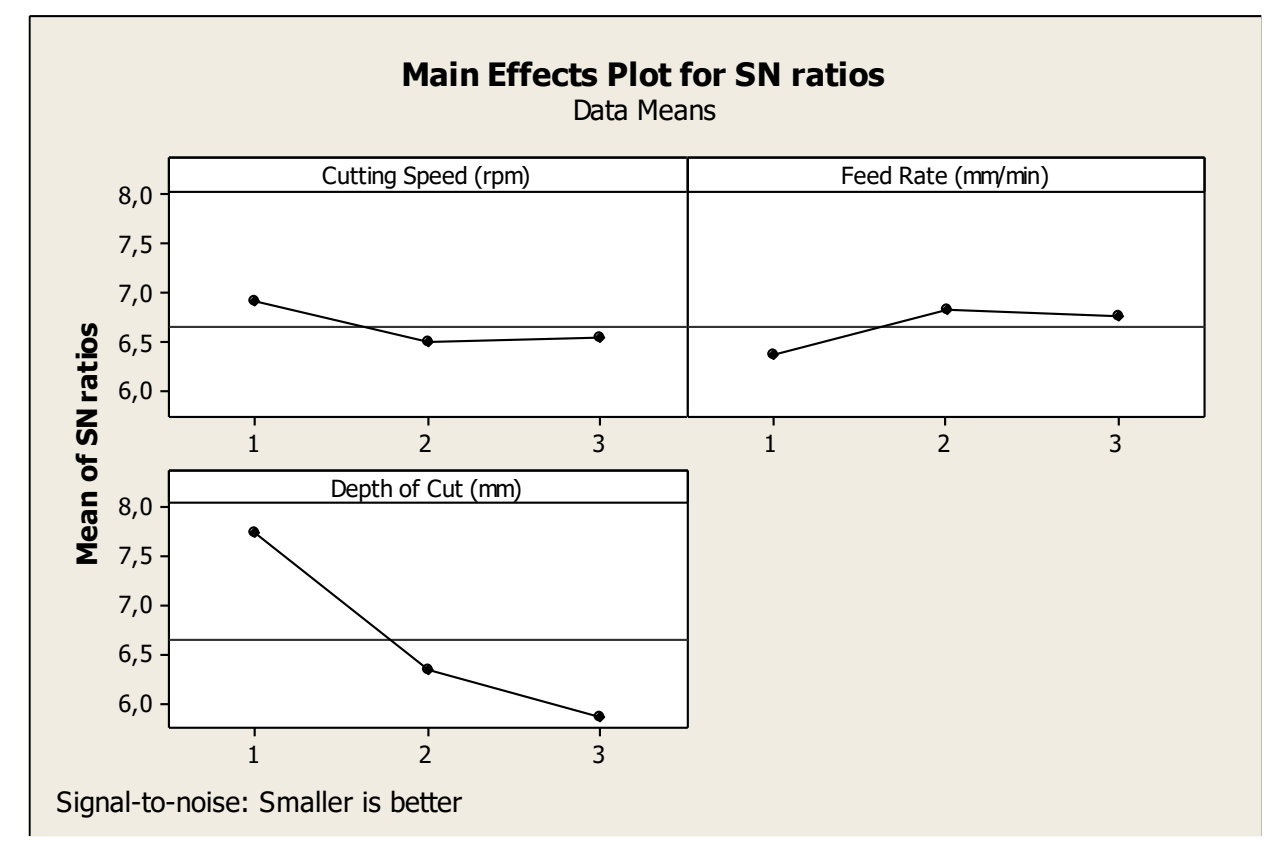

Şekil 2. Yüzey Pürüzlülüğü için SN Oranı 


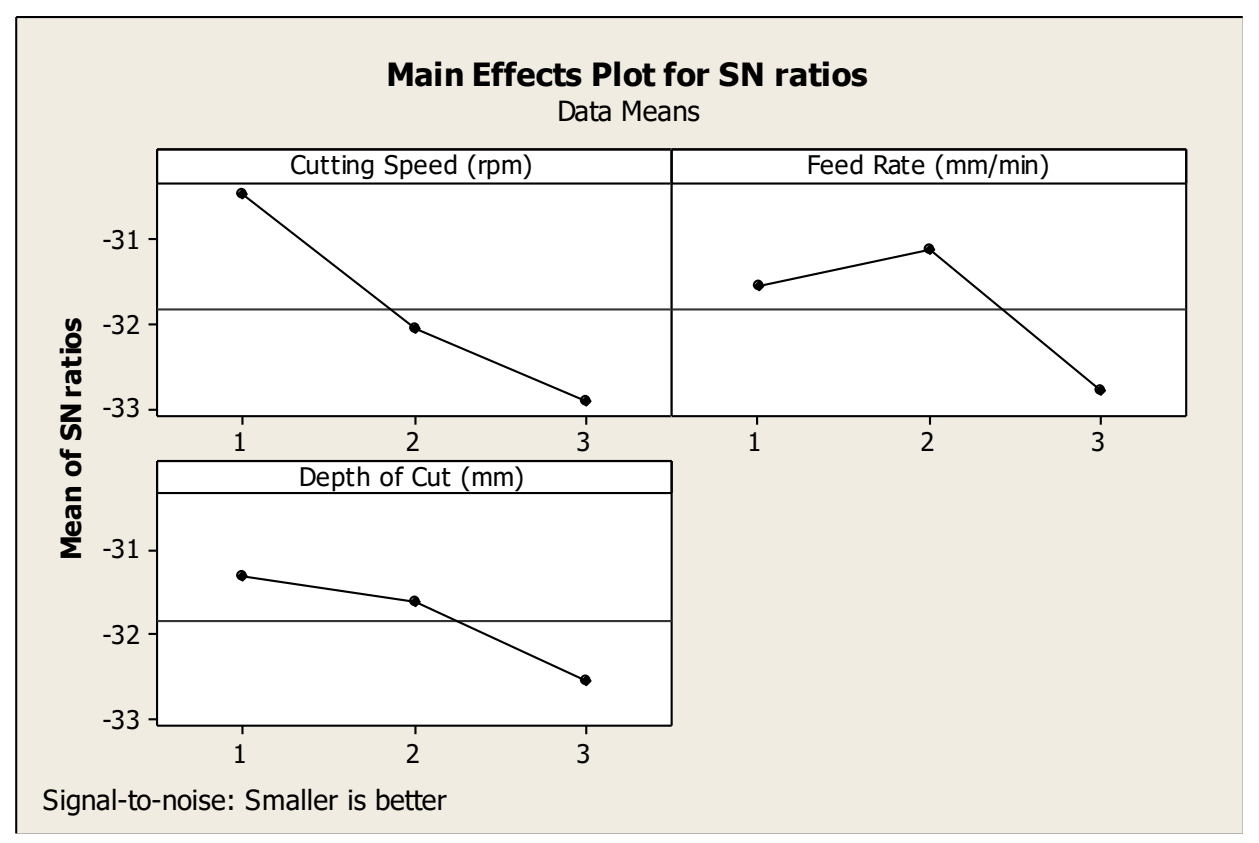

Şekil 3. Kesme Kuvveti için SN Oranı

Magnezyum malzeme üzerinden DLC kaplı DL10 parmak freze takımlarla CNC freze tezgahında devir, ilerleme ve talaş derinliği parametreleri değişken olarak kullanılarak talaş kaldırılmıştır. Bu işleme parametrelerinin yüzey pürüzlülüğüne etkileri incelenmiştir.

Tablo 5'de deneyler sonrası elde edilen yüzey pürüzlülük ve kesme kuvvet değerleri verilmiştir. Genel olarak, elde edilen pürüzlülük değeri, 0.384- $0.56 \mu \mathrm{m}$ arasında, kesme kuvvetleri ise 31.28-52.64 $\mathrm{N}$ arasında olmuştur.

Tablo 5. Deneyler Sonucu Ölçülen Yüzey Pürüzlülüğü Ve Kesme Kuvveti Değerleri

\begin{tabular}{cccc}
\hline $\begin{array}{c}\text { Deney } \\
\text { No. }\end{array}$ & Değişikenler & $\begin{array}{c}\text { Yüzey } \\
\text { Pürüzlülüğüü } \\
(\mu \mathrm{m})\end{array}$ & $\begin{array}{c}\text { Kesme } \\
\text { Kuvveti } \\
(\mathrm{N})\end{array}$ \\
\hline 1 & $\mathrm{~A}_{1} \mathrm{~B}_{1} \mathrm{C}_{1}$ & 0.384 & 31.28 \\
2 & $\mathrm{~A}_{1} \mathrm{~B}_{2} \mathrm{C}_{2}$ & 0.444 & 33.87 \\
3 & $\mathrm{~A}_{1} \mathrm{~B}_{3} \mathrm{C}_{3}$ & 0.538 & 35.25 \\
4 & $\mathrm{~A}_{2} \mathrm{~B}_{1} \mathrm{C}_{2}$ & 0.56 & 32.96 \\
5 & $\mathrm{~A}_{2} \mathrm{~B}_{2} \mathrm{C}_{3}$ & 0.476 & 41.20 \\
6 & $\mathrm{~A}_{2} \mathrm{~B}_{3} \mathrm{C}_{1}$ & 0.398 & 47.61 \\
7 & $\mathrm{~A}_{3} \mathrm{~B}_{1} \mathrm{C}_{3}$ & 0.516 & 52.64 \\
8 & $\mathrm{~A}_{3} \mathrm{~B}_{2} \mathrm{C}_{1}$ & 0.449 & 33.42 \\
9 & $\mathrm{~A}_{3} \mathrm{~B}_{3} \mathrm{C}_{2}$ & 0.451 & 49.44 \\
\hline
\end{tabular}

\subsection{Gri İlişkisel Analiz Sonuçlart}

Magnezyumun işlenmesinde yüzey pürüzlülügünün ve kesme kuvvetinin az olması istenmektedir. Bundan dolayı GİA yöntemine göre referans serisi oluşturulurken minimum değerler göz önüne alınır ve normalizasyon işlemi esnasında "daha düşük daha iyi" şeklinde değerlendirilir. 
Bütün ölçüm sonuçların normalize edilmiş hali ve hesaplanan katsayı matrisi sonuçları Tablo 6'da sunulmuştur. Katsayı matrisleri hesaplandıktan sonra, Eşitlik 11'e göre Gri İlişkisel Dereceleri bulunur. Uygulanan deneye göre, Tablo 6' da ve Şekil 2'de de açıkça görüldüğü gibi Gri İlişkisel Derecelerinde en yüksek (optimum) değer 1 numaralı deneyden elde edilmiştir. Çıkan sonuçlar göre en yüksek olan değer en ideal değer olarak tanımlanır. Gri İlişkisel Dereceye göre minimum yüzey pürüzlülüğü ve kesme kuvveti değeri elde etmek için kullanılacak en ideal kesme özellikleri 1 numaralı deneyde kullanılan işleme şartlarında görülmektedir.

Tablo 6. Gri İlişkisel Analiz Değerleri

\begin{tabular}{l|c|c|c|c|cc}
\hline $\begin{array}{l}\text { Deney } \\
\text { No }\end{array}$ & \multicolumn{2}{|c|}{ Normalizasyon } & \multicolumn{2}{c|}{ Katsayı Matrisi } & \multicolumn{2}{c}{ Gri İlişkisel Derece } \\
\hline & $\begin{array}{c}\text { Yüzey } \\
\text { Pürüzlülü̆ğü }\end{array}$ & $\begin{array}{c}\text { Kesme } \\
\text { Kuvveti }\end{array}$ & $\begin{array}{c}\text { Yüzey } \\
\text { Pürüzlülüğü }\end{array}$ & $\begin{array}{c}\text { Kesme } \\
\text { Kuvveti }\end{array}$ & $\begin{array}{c}\text { Gri } \\
\text { Derece }\end{array}$ & $\begin{array}{c}\text { GíA } \\
\text { Sıralaması }\end{array}$ \\
\hline 1 & 0,000 & 0,000 & 1,000 & 1,000 & 1,000 & 1 \\
2 & 0,341 & 0,121 & 0,595 & 0,805 & 0,700 & 3 \\
3 & 0,875 & 0,186 & 0,364 & 0,729 & 0,546 & 6 \\
4 & 1,000 & 0,079 & 0,333 & 0,864 & 0,599 & 5 \\
5 & 0,523 & 0,464 & 0,489 & 0,518 & 0,504 & 7 \\
6 & 0,080 & 0,765 & 0,863 & 0,395 & 0,629 & 4 \\
7 & 0,750 & 1,000 & 0,400 & 0,333 & 0,367 & 9 \\
9 & 0,369 & 0,100 & 0,575 & 0,833 & 0,704 & 2 \\
\end{tabular}

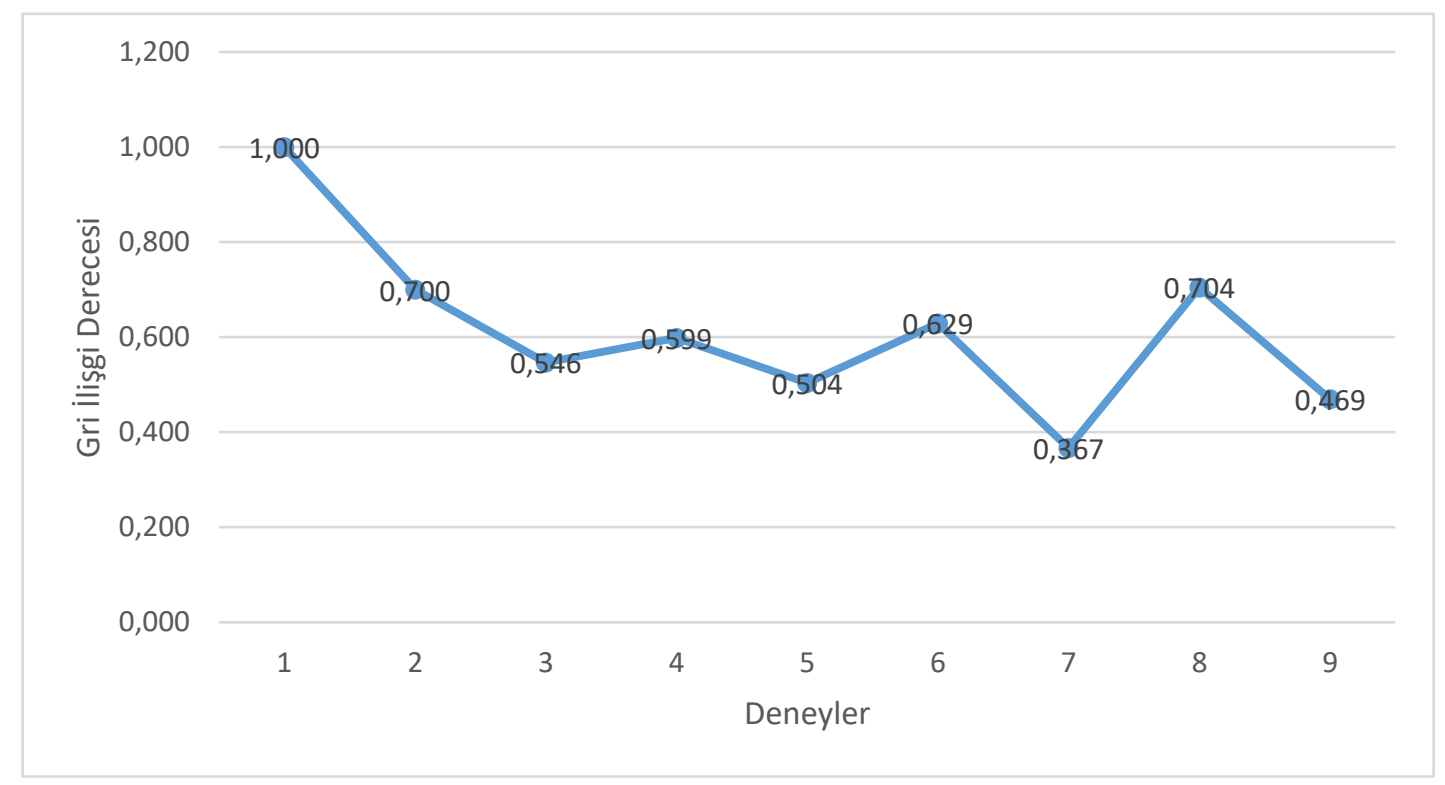

Şekil 4. Gri İlişkisel Derece 
Tablo 7. İşleme Için Gri İlişkisel Analiz Değerleri

\begin{tabular}{lccc}
\hline Levels & $\begin{array}{c}\text { Spindle Speed } \\
(\mathbf{m} / \mathbf{m i n})\end{array}$ & Feed $(\mathbf{m m} / \mathbf{m i n})$ & $\begin{array}{c}\text { Depth of } \\
\text { Cutting(mm) }\end{array}$ \\
\hline Level 1 & $\mathbf{0 , 7 4 9}$ & $\mathbf{0 , 6 5 5}$ & $\mathbf{0 , 7 7 8}$ \\
Level 2 & 0,577 & 0,636 & 0,589 \\
Level 3 & 0,513 & 0,548 & 0,472
\end{tabular}

\section{Sonuç ve Tartışma}

AZ91 alaşım malzemesinin DLC kaplı parmak freze ile işlenebilirliğinin araştırıldığı bu çalışmada faydalı neticeler elde edilmiştir. İşlenebilirlik için incelenen kriterler, yüzey pürüzlülüğü ve kesme oluşumun olmuştur. Bu kriterlerin en ideal şartlarda gerçekleşmesinde etkili olduğu düşünülen üç kontrol faktörü (Devir, ilerleme oranı ve talaş derinliği) üç farklı seviyede seçilmiş ve deneysel çalışmada uygulanmıştır. Bulunan neticeler aşağıda özetlenmiştir.

- AZ91 alaşım malzemesinin DLC kaplamalı kesici takımlarla işlenmesinde, en iyi yüzey pürüzlülük değerine (Ra: $0.384 \mu \mathrm{m}$ ) devir $9000 \mathrm{dev} /$ dak, ilerleme oranı 800 $\mathrm{mm} /$ dak ve talaş derinliği $0.5 \mathrm{~mm}$ ile elde edilmiştir.

- Kesme kuvvetinin oluşumunda her üç kontrol faktörü (ilerleme oranı, kesme hızı ve talaş derinliği) de etkili olmuştur. En düşük kesme kuvveti değerine (31.28), devir $9000 \mathrm{dev} / \mathrm{dak}$, ilerleme oranı $900 \mathrm{~mm} / \mathrm{dak}$, ve talaş derinliği $0.5 \mathrm{~mm}$ 'de ulaşılmıştır.

- Taguchi optimizasyon tekniği, AZ91 alaşım malzemesinin işlenebilirliği deney tasarımında ve parametrelerin optimizasyonu ile yanıt değerlerin istenilen oranlarda seyretmesinde etkili bir teknik olduğu yapılan çalışma ile görülmüştür.

- GRİ ilişkisel optimizasyon tekniği ile yüzey pürüzlülüğü ve kesme kuvveti optimize edilmiş ve devir $9000 \mathrm{dev} / \mathrm{dak}$, ilerleme oran1 $900 \mathrm{~mm} / \mathrm{dak}$, ve talaş derinliği $0.5 \mathrm{~mm}$ ile ulaşılmıştır.

Elde edilen sonuçlar ve literatür dikkate alınarak değerlendirildiğinde, DLC kaplamaların AZ91 alaşım malzemesinin işlenebilirliğine olumlu katkı sağladığı ve özellikle kesici takımın performansındaki iyileşmeye ivme kazandırdığı sonucuna ulaşılmıştır.

\section{Kaynaklar}

[1] Kandemir, K., Can, A. Ç., "Otomotiv Endüstrisi İçin Magnezyum Alaşımlarının Kullanım Potansiyeli” Pamukkale Üniversitesi Mühendislik Fakültesi Mühendislik Bilimleri Dergisi, 2003,1.37-45.

[2] Zeytin, H. K., "Magnezyum Alaşımları: Otomotiv Endüstrisinde Uygulaması ve Geleceği” Marmara Araştırma Merkezi, Gebze, Kocaeli 1999.

[3] Ünal, M., "Magnezyum Alaşımlarının Döküm Özelliklerinin İncelenmesi” Doktora Tezi, Gazi Üniversitesi, Fen Bilimleri Enstitüsü, Ankara, 2008.

[4] Gaines, L., Cuenca, R., Stodolsky, F., WU, S, "Potential Automotive Uses of Wrought Magnesium Alloys" Automotive Technology Development, 1-7. Detroit, Michigan, 1996. 
[5] Ünal, M., Koç, E.,Türen, Y., Gül, F., Candan, E., "AZ91 Magnezyum Alaşımının Döküm ve Mekanik Özelliklerine Si İlavesinin Etkisi”, V. International Advanced Technologies Symposium, 13-15 May, Karabük, Turkey. 2009.

[6] Koç, E., Ünal, M., Türen, Y., Candan, E., "AZ91 Magnezyum Alaşımının Döküm ve Mekanik Özelliklerine Sn İlavesinin Etkisi”, V. International Advanced Technologies Symposium, 13-15 May, Karabük, Turkey. 2009.

[7] Saklakoğlu, N., Erçayhan, Y., “AZ91 Magnezyum Alaşımının Metalurjik Özelliklerine Kadmiyum Elementinin Etkisi” II. Ulusal Tasarım -İmalat ve Analiz Kongresi (TIMAK) 11-12 Kasım, Balıkesir, 2010.

[8] Akyüz, B., "Influence of Al content on machinability of AZ series $\mathrm{Mg}$ alloys" Transactions of Nonferrous Metals Society Of China, 2013;23: 2243-2249.

[9] Kim, J., Lee, K., "Surface Roughness Evaluation in Dry-Cutting of Magnesium Alloy by Air Pressure Coolant" Engineering, 2010;2;p.788-792.

[10] Narıta, H., Katoh, K., Tokısue, H., "Facing Machinability of AZ91 Magnesium Alloy Castings" Journal of Japan Institute of Light Metals Vol. 51 No. 11 P 614-618 (2001).

[11] Ay, M., Etyemez, A. Optimization of Effects of Cutting Parameters and Cutting Tool Path by using Grey Based Taguchi Method. Acta Physica Polonica, A, 2018;134-1p.125-128.

[12] Ay, M. Optimisation of Machining Parameters in Turning AISI 304L Stainless Steel by the Grey-Based Taguchi Method. Acta Physica Polonica, A, 2017;131-3p.349-353.

[13] Basmaci G., Ay M. Optimization of Cutting Parameters, Condition and Geometry in Turning AISI 316L Stainless Steel Using the Grey-Based Taguchi Method. Acta Physica Polonica, A, 2017;131-3 p.354-358.

[14] Basmaci G., Ay M. Etyemez, A. The Grey-Based Taguchi Method: Optimization of Milling of Mold Steel. Acta Physica Polonica, A, 2018;134-1 p.24-27.

[15] Etyemez, A. Optimization of Effects of Pocket Tool Path Strategies and Cutting Parameters on Surface Quality. Acta Physica Polonica A, 2016;129-4 p.886-889. 